Document downloaded from:

http://hdl.handle.net/10251/75161

This paper must be cited as:

Garcia-Prats, A.; Guillem Picó, S. (2016). Adaptation of pressurized irrigation networks to new strategies ofirrigation management: Energy implications of low discharge andpulsed irrigation. Agricultural Water Management. 169:52-60. doi:10.1016/j.agwat.2016.02.023.

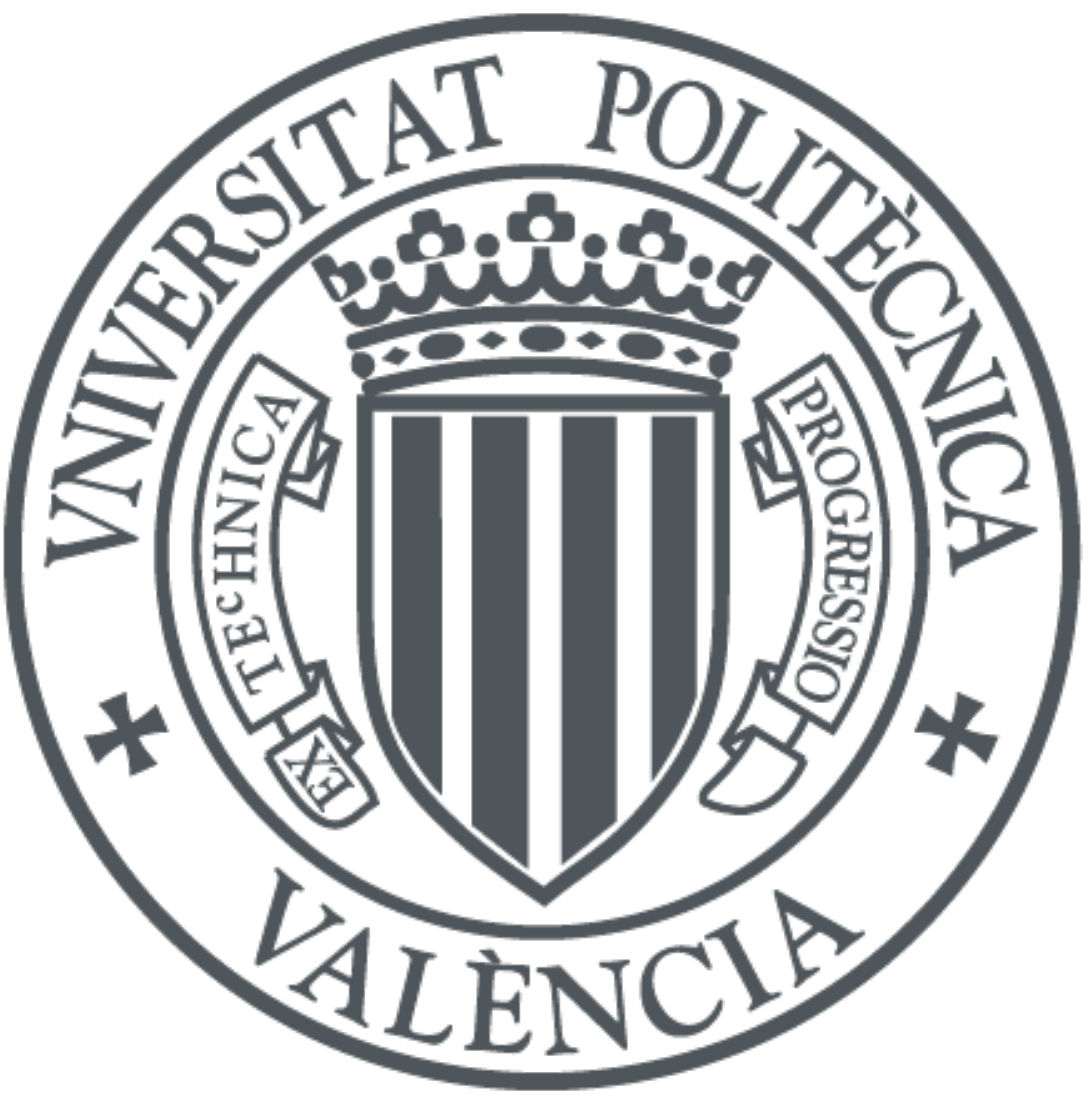

The final publication is available at

https://dx.doi.org/10.1016/j.agwat.2016.02.023

Copyright Elsevier Masson

Additional Information 


\section{ADAPTATION OF PRESSURIZED IRRIGATION NETWORKS TO NEW STRATEGIES OF IRRIGATION MANAGEMENT: ENERGY IMPLICATIONS OF LOW DISCHARGE AND PULSED IRRIGATION}

García-Prats, Alberto ${ }^{1 *}$; Guillem-Picó, Santiago ${ }^{2}$

\section{ABSTRACT}

This paper analyzes the consequences of adopting new on-farm irrigation management strategies (low discharge rates, long irrigation times and high frequencies) in an existing ondemand and sectorized pressurized irrigation system in eastern Spain. The sectorized behavior of the network was analyzed using two criteria: i) the operating sectors obtained in a first stage by arranging the hydrants depending on their altitude respecting the pumping station and ii) the operating sectors obtained by means of an optimization process. The Simulated Annealing combinatorial metaheuristic optimization technique was employed to find the best solution. Random on-demand patterns were generated using a Montecarlo simulation. The hydraulic requirements of the network were analyzed in every scenario by the Epanet 2.0 engine. The effect on energy consumption, power requirements and energy costs was assessed taking into account the electricity tariff billing structure. It was found that reductions in emitter discharge $\left(q_{e}\right)$ and Energy consumption $(E)$-Energy Cost $(E C)$ savings are not inherently related to each other. Certain amounts of $E$ and $E C$ could be saved when the number of sectors and operating time parameters were properly selected. Pulsed irrigation in the current scenario showed an energy saving potential of $10.67,6.43$ and $6.99 \%$ for power capacity, $E$ and $E C$, respectively.

\footnotetext{
${ }^{1}$ Research Institute of Environmental Engineering, Universitat Politècnica de València. Camino de Vera s/n. 46022. Valencia. Spain. E-mail: agprats@upvnet.upv.es.

${ }^{2}$ Departamento de Ingeniería Cartográfica, Geodesia y Fotogrametría, Universitat Politècnica de València. Camino de Vera s/n. 46022. Valencia. Spain.

* Corresponding author, e-mail: agprats@upvnet.upv.es
} 
1 Keywords: Energy optimization; on-demand and sectorized performance; pressurized irrigation

2 network; Continuous irrigation irrigation; pulsed irrigation.

3 HIGHLIGHTS

- Consequences of adopting new on-farm irrigation management strategies on energy consumption and electric costs in a pressurized irrigation network were analyzed.

- Reductions of emitter discharge and energy consumption or energy cost savings are not inherently related to each other.

8 - Pulsed irrigation in the current scenario showed an energy saving potential.

9

10

\section{LIST OF TABLES}

11 Table 1. Usage period-related 2015 electricity tariffs.

12 Table 2. Scenarios analyzed under continuous and pulsed irrigation.

13 Table 3. Increase in $P_{\text {abs }}(\mathrm{kW}), E(\mathrm{~kW} \cdot \mathrm{h})$ and $E C(€)$ over Scenario 1, excluding Scenarios 2 and 143

17 Figure 1. Evolution of $P_{\text {abs }}(\mathrm{kW}), E(\mathrm{~kW} \cdot \mathrm{h})$ and $E C(€)$ in different scenarios of continuous 18 irrigation.

19 Figure 2. Evolution of $P_{\text {abs }}(\mathrm{kW}), E(\mathrm{~kW} \cdot \mathrm{h})$ and $E C(€)$ in different scenarios of pulsed 20 irrigation. 


\section{Introduction}

In many Mediterranean countries traditional irrigation schemes have been modernized during the last two decades. This updating of the irrigation facilities consisted of substituting ancient open-cannals-based transport, distribution, and surface watering systems by pressurized piping systems (Plusquellec 2009) in an attempt to achieve several advantages: a) reduce water losses during transport and application, b) overcome topographic constraints, c) avoid uncontrolled water withdrawals, and d) invoice the exact amount of water consumed on each farm (Lamaddalena and Sagardoy, 2000; Daccache et al., 2010). In addition, pressurized irrigation networks make it possible to implement new and more efficient on-farm irrigation systems, mainly drip and sprinkler irrigation. This entire process has derived in an increase of the water use efficiency but simultaneously it involves a notably increase in energy consumption (IDAE, 2008), especially in sprinkler irrigation. Many studies can be found in the literature aimed at assessing the behavior of pressurized irrigation networks in order to improve their energy consumption (Fernandez et al., 2013, 2014, 2015; Diaz et al., 2009; García-Prats, 2012; Gonzalez et al., 2014; Jimenez-Bello et al., 2010, 2015; Rodriguez Diaz et al., 2007, 2012; Tarjuelo et al., 2015;). The large number of these studies is an indication of the importance of this issue.

Drip irrigation has been traditionally recommended for row crops, vines and trees (Brouwer et al., 1988) although its many proven advantages has meant that its use has been extended to almost all types of crops. Its most significant advantages include: i) higher water use efficiency (Daccache et al., 2010), ii) lower energy requirements than other pressurized irrigation systems and iii) higher yields and better quality of harvested crops (Vyrlas and Sakellariou, 2005). The increased use of drip irrigation is seen as one way of improving the sustainability of irrigation systems around the world (Cote at al., 2003). The potential efficiency of drip irrigation is generally accepted to be around $90 \%$, however we should not lose sight of the fact that this value is not an inherent property of the system, but a function of its management (Smith, 2010). 
1 Discharge rates and irrigation times and frequencies are the most important management-related

2 parameters.

3 Continuous irrigation (sometimes named microdrip irrigation in the literature) is defined as a

4 drip irrigation system that supplies water at a rate close to that of plant water uptake in order to

5 improve irrigation efficiency and yields and reduce water losses from drainage below the root

6 zone (Assouline et al., 2002a, 2002b). However, soil moisture regimes similar to those resulting

7 from continual low water application rates can be achieved by means of pulsed drip irrigation at

8 higher discharge rates (Phogat et al., 2013). Pulsing involves the application of the same total

9 amount of water and irrigation time but in a phased manner, i.e. fractioned into a series of on-off

10 irrigation cycles.

11 Searching for the best management system to make the most of drip irrigation, several recent works deal with different management strategies in a combination of continuous and pulsed irrigation (Assouline, 2002; Assouline et al., 2002; Elnesr et al., 2015; Elnesr and Alazba, 2015;

14 Segal et al., 2006; Vyrlas and Sakellariou, 2005; Phogat et al., 2012-2013; Skaggs et al., 2010;

15 Elmaloglou and Diamantopoulos, 2007; and Cote at al., 2003). In several cases they found enhanced yields, efficiency, salt distribution and fertilizer leaching using low rates, high

17 frequency and pulsed irrigation. In other cases they found no differences between management strategies, but in no case have worse results been reported from continuous or pulsed irrigation. Hence, both these methods are promising fields that should be considered in order to achieve more efficient use of irrigation water, but not only on the farms themselves, since overall efficiency is the product of all the efficiencies obtained from the entire network (storage, conveyance, distribution, application, etc).

23 Due to the interaction between the pressurized irrigation network, its pumping station and on24 farm irrigation systems (Lamadalena et al., 2007; Daccache et al., 2010; Gonzalez et al., 2014), 25 it could be expected that any change on the irrigation management strategy would have new associated scenarios with different headlosses in pipes and requirements for operating time, total 
1 discharge and pressure head in the pumping station in comparison to those one of the currently

2 used system. In addition, every new scenario will have other associated energy implications,

3 related not only to energy consumption, but also to the electricity billing structure. These

4 consequences could be expected to be different if the pressurized irrigation network was

5 planned to perform on-demand or sectorized.

6 Hence, the objective ofthis work was to analyze the consequences of adopting new strategies of 7 on-farm irrigation management (low discharge rates, large irrigation times and high frequencies)

8 in a pressurized on-demand and sectorized irrigation network in the east of Spain, taking into 9 consideration the interaction all those new strategies with the electricity tariff billing structure.

\section{Method}

\subsection{Discharge calculations of on-demand performance}

13 A lot of pressurized irrigation networks have been scheduled to work on-demand; water is 14 delivered from the network with enough pressure to meet the on-farm irrigation system requirements, and the farmer to decide the duration and frequency of operation. The number of hydrants that operates at the same time is determined using a stochastic process. Divers methods can be found in the literature to determine the network discharge when operates on-demand. We used the Clément's 1st formula method (Clément, 1966), in which the state of each hydrant (open or closed) is supposed to fit a binomial statistical distribution, tending to a normalGaussian statistical distribution whether the number of hydrants operating is sufficiently high.

When a network operates on-demand, its pumping station have to be prepared to provide the maximum discharge rate equivalent to the envelope of all possible discharge rates for a certain operation quality (Lamaddalena and Sargadoy, 2000; Moreno et al., 2007). At the same time has to provide enough pressure at the origin of the network (pumping station) to ensure that at the most unfavorable hydrant the pressure head is greater than the minimum required to operate the 
on-farm irrigation system. Nonetheless, the same discharge flow-rate $Q_{\mathrm{di}}$ could be obtained from many different open-hydrant combinations, each of them requiring their own pressure $H_{\mathrm{i}}$. Hence, whilst the network is operating it is stochastically drawing a cloud of pairs of values $Q_{\mathrm{di}}-$ $H_{\mathrm{i}}$, that depends on what hydrants are opened at that moment.

Therefore, each combination of opened hydrants involves a pump operating point $\left(Q_{\mathrm{di}}-H_{\mathrm{i}}-\eta_{\mathrm{i}}\right)$ with a specific energy consumption.

\section{Clément Method}

In the Clément's 1st formula method, the discharge flow-rate at the origin of the network associated to a certain probability $P_{\mathrm{q}}$ of not being exceeded (Clément, 1966) is obtained as follows:

$$
Q_{d}=\sum_{i=1}^{n} p_{i} d_{i}+U\left(P_{q}\right) \sqrt{\sum_{i=1}^{n} p_{i} q_{i} d_{i}^{2}}
$$

where $Q_{\mathrm{d}}$ is the discharge flow-rate $\left(\mathrm{L} \mathrm{s}^{-1}\right)$ at the origin of the network that supplies $n$ hydrants associated to a probability $P_{\mathrm{q}}$ of not being exceeded (It should be noted that $P_{\mathrm{q}}$ is named supply guarantee or operation quality $-O Q$ - as well, i.e. is the probability to meet the desired flow and pressure conditions in the network when the user decides to water); $p_{\mathrm{i}}$ is the probability of finding the hydrant $i$ open; $q_{\mathrm{i}}=1-p_{\mathrm{i}}$ is the probability of finding the hydrant $i$ closed; $d_{\mathrm{i}}$ is the nominal discharge $\left(\mathrm{L} \mathrm{s}^{-1}\right)$ of hydrant $i$; and $U\left(P_{\mathrm{q}}\right)$ is the standard normal cumulative variable for probability $P_{\mathrm{q}}$.

1st Clément's model is based on two hypotheses: (a) the state of the hydrant (open or closed) fits a binomial statistical distribution and each hydrant operates independently and at random. (b) Every hydrant has the same opening probability to each other at any time of the day and at any day of the week (Rodriguez Diaz et al., 2007; Monserrat et al., 2004). When enough hydrants downstream are operating, the discharge flow-rate fits a normal-Gaussian statistical distribution. Hence, the average opening probability of each hydrant $i$ (Moreno, et al., 2007) can be calculated as: 


$$
p_{i}=\frac{N_{s} t_{r}}{\text { OT IR }}=\frac{t_{d}}{\text { OT }}
$$

2

where $N_{\mathrm{s}}$ is the number of drip irrigation subunits per farm; $O T$ is the network daily operation

4 time $\left(\mathrm{h} \mathrm{d}^{-1}\right) ; t_{\mathrm{r}}$ is the irrigation time to meet the crop water needs $(\mathrm{h}) ; I R$ is theirrigation interval

5 (d); and $t_{\mathrm{d}}$ is the average daily irrigation time $\left(\mathrm{h} \mathrm{d}^{-1}\right)$.

6 For each hydrant, the nominal discharge $d_{\mathrm{i}}$ was calculated as follows(Alandi, et al., 2001):

7

$$
d_{i}=A_{r s} \frac{\mathrm{S}_{\mathrm{i}}}{\mathrm{N}_{\mathrm{s}}} 2.778
$$

8 being 2.778 a coefficient to adapt units $\left(\frac{10,000 \mathrm{~m}^{2} \mathrm{ha}^{-1}}{3,600 \mathrm{~s} \mathrm{~h}^{-1}}\right) ; A_{r s}$ is the average on-farm irrigation

9 system application rate $\left(\mathrm{L} \mathrm{m}^{-2} \mathrm{~h}^{-1}\right) ; S_{\mathrm{i}}$ is theplot area (ha).

10 The irrigation time needed to meet the crop water needs was obtained as follows (Alandi, et al. 11 2001):

$$
\mathrm{t}_{\mathrm{r}}=\frac{\mathrm{IR} \mathrm{NT}}{\mathrm{A}_{\mathrm{rs}}}
$$

where $N T_{\mathrm{r}}$ is the peak period crop gross irrigation needs $\left(\mathrm{L} \mathrm{m}^{-2} \mathrm{~d}^{-1}\right)$.

\section{Montecarlo simulation}

Following Moreno, et al. (2007), Clément's method can be transformed () to:

$$
\mathrm{Q}_{\mathrm{d}}=\mu+\mathrm{U}\left(\mathrm{P}_{\mathrm{q}}\right) \sigma
$$

17 where $\mu$ is the mean of normal density function equivalent in this case to the average discharge

18 flow-rate, and $\sigma$ is the standard deviation of discharge flow-rate.

19 Therefore, it was able to conduct a Montecarlo simulation in which the state (open or closed) of each hydrant was defined as a stochastic variable $r_{\mathrm{i}}$ with a binomial performance. The 
1 probability of finding a hydrant open, as was previously defined, is known and is equal to $p_{\text {i. }}$.

2 When in an iteration of the Montecarlo simulation, the random variable takes the value $r_{\mathrm{i}}=1$,

3 hydrant $i$ is open and produces a discharge equal to the nominal discharge $d_{\mathrm{i}}$. When the random

4 variable takes the value $r_{\mathrm{i}}=0$, that hydrant is closed and any discharge will be done. In each

5 iteration the discharge flow-rate at the origin of the network was calculated as:

$$
\mathrm{Q}_{\mathrm{di}}=\sum_{\mathrm{i}=1}^{\mathrm{n}} \mathrm{r}_{\mathrm{i}} \mathrm{d}_{\mathrm{i}}
$$

After enough iterations (identified because the average discharge flow-rate $\mu$ does not change up to a specific tolerance with further iterations) is possible to obtain the average discharge flow-rate, the standard deviation (previously defined as $\sigma$ in Eq.(5)), as well as the $Q_{\mathrm{d}}$ for all the percentiles without needing to apply Clément's 1st formula. Note that the result obtained when Eq.(5) is applied with a given operation quality $(O Q)$ is tantamount to the one obtained in the Montecarlo simulation for a percentile equals to $O Q$.

The main benefit of using a Montecarlo simulation procedure instead of a single design discharge flow-rate, as it happens when the Clément's 1st formula is used, is that multiple scenarios of stochastically generated open-hydrant combinations can be derived. Each of these combinations can be further analyzed using Epanet and $H_{\mathrm{i}}$ values associated to each value of $Q_{\text {di }}$ obtained.

\section{Effect of pulsing irrigation}

As previously mentioned, pulsed drip irrigation involves the same amount of water and time as continuous drip irrigation, but divided into a number of phases. To put it into practice, the network manager has to divide operation time by the number of irrigation cycles. For example, if $t_{\mathrm{d}}=3 \mathrm{~h}$ and $O T=15 \mathrm{~h}$ and pulsed irrigation is done in three pulses, the farmer has water three times a day with $1 / 3 \cdot t_{\mathrm{d}}=1 \mathrm{~h}$ per cycle: the first from 1 to $5 \mathrm{~h}$, the second from 6 to 10 , and the last from 11 to $15 \mathrm{~h}$ with total freedom in each period. The effect on the random pattern generation is related to the statistical concepts of the Central Limit Theorem and the Principle of 
1 Diversification. Splitting $O T$ into three independent periods, the behavior of a given hydrant

2 throughout the day is the mean value of three independent random variables with the same

3 opening probability $\left(\mathrm{p}_{\mathrm{i}}=\frac{\mathrm{t}_{\mathrm{d}}}{\mathrm{OT}}=\frac{1}{5}=\frac{3}{15}=0.2\right)$ with binomial behavior. Consequently, a similar

4 mean value of $Q_{\mathrm{di}}$ is obtained, but with a substantial reduction in the variance. Further

5 information on the diversification principle can be found in Savage (2003) and Rachev et al.

6 (2006).

\section{$7 \quad$ 2.2. Calculating discharge in operating-sector operations}

8 Many studies have confirmed that on-demand pressurized irrigation networks have large energy 9 requirements (García-Prats et al., 2012; Jiménez-Bello, 2015). An existing alternative to the on10 demand performance is to divide the network into turns named operating sectors as well. A 11 group of hydrants operating simultaneously at a given time form a turn or operating sector 12 (García-Prats, 2012). As was aforementioned, the nominal discharge of each hydrant $d_{\mathrm{i}}$ could be derived from the Eq.(3). Hence,the total discharge flow-rate of an operating sector $Q_{\text {si }}$ could be obtained by summing the discharges of those hydrants that operates simultaneously during a given period:

$$
\mathrm{Q}_{\mathrm{si}}=\sum_{\mathrm{i}=1}^{\mathrm{n}} \mathrm{d}_{\mathrm{i}}
$$

$17 N S$ is the number of turns or operating sectors and have to be consistent with the daily time required per hydrant to water $\left(t_{\mathrm{d}}\right)$ with the purpose to be capable of providing water to overall the network's hydrants along the daily operation time $(O T)$.

$$
O T \geq \mathrm{NS} t_{d}
$$

\section{Effect of pulsing irrigation}

In contrast to on-demand, in sectorized performance no effects were expected due to pulsed irrigation management. A turn or operating sector has been defined as a group of hydrants that operates simultaneously at a given time. Each time these hydrants work together, the same point 
$1 Q_{\mathrm{si}}-H_{\mathrm{i}}-\eta_{\mathrm{i}}$ will be obtained, so that power capacity demand and energy consumption will also be

2 the same.

\section{2.3. Hydraulic Simulation: Pressure head requirements per scenario}

6 Each open-hydrant combination do not only produces a turn or sector but a hydraulic scenario

7 as well, regardless whether its type of performance is on-demand or sectorized. Therefore, each

8 hydraulic scenario will require a certain value of pressure at the origin of the network $H_{\mathrm{i}}$, in

9 order to guarantee the minimum pressure condition in the worst-pressure hydrant. $H_{\mathrm{i}}$ was

10 obtained using software of hydraulic simulation, specifically Epanet V2 model (Rossman,

11 2000). EPANET is public domain software developed by the Environmental Protection Agency

12 (EPA) of the United States, which models pressurized pipe networks and performs extended

13 period simulations of the water movement and quality behavior. The result of the hydraulic

14 simulation is composed by pairs of values, $Q_{\mathrm{si}}-H_{\mathrm{i}}$ or $Q_{\mathrm{di}}-H_{\mathrm{i}}$, as appropriate.

It should be noted that the worst-pressure hydrant for each scenario was selected among the opened hydrants. Non-operating hydrants only require positive pressures.

\subsection{Energy Consumption and Pumping Station Regulation}

The efficiency $(Q-\eta)$ and characteristic $(Q-H)$ curve of commercial pumps with fixed-speed at nominal revs can be approached as follows (Planells, et al., 2005):

$$
\left\{\begin{array}{l}
H=C+D^{2} \\
\eta=E Q+F Q^{2}
\end{array}\right.
$$

where $H$ is the pressure (m) produced by a pump unit when the discharge flow-rate is $Q\left(\mathrm{~L} \mathrm{~s}^{-1}\right)$; $\eta$ is the pump efficiency (\%); C, D, E, $F$ are the pump parameters derived from the characteristic curves provided by the pump manufacturer; 
2 Eq.(9) can be adapted to work with pumps of variable speed using the affinity laws (Planells, et 3 al., 2005):

4

$$
\left\{\begin{array}{l}
H=\alpha^{2} \mathrm{C}+\mathrm{DQ}_{1}{ }^{2} \\
\eta=\frac{\mathrm{E}}{\alpha} \mathrm{Q}_{1}+\frac{\mathrm{F}}{\alpha^{2}} \mathrm{Q}_{1}{ }^{2}
\end{array}\right.
$$

5 Where $N_{0}$ is the nominal pump revs; $\alpha$ is the pump relative speed $\left(\alpha=N_{\mathrm{p}} / N_{0}\right) ;, N_{\mathrm{p}}$ is the pump

6 revs at a given time; $Q_{1}$ is the discharge flow-rate of one variable-speed pump whether the $7 \quad$ pressure was $H$ and the pump spins at $\alpha$ relative revs.

8 The required power capacity of each hydraulic scenario in a pumping station composed of $N_{\mathrm{fs}}$ equal fixed-speed pump units and $N_{\mathrm{vs}}$ equal variable-speed pump units arranged in parallel could be obtained as follows (Planells, et al., 2005):

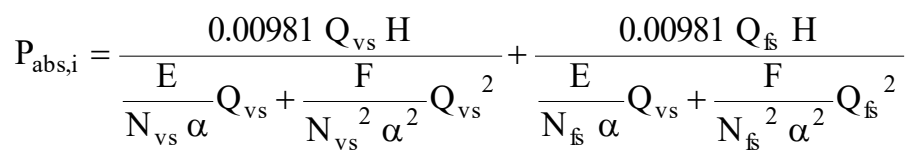

where $Q_{\mathrm{vs}}$ is the total discharge flow-rate of variable speed pump units $\left(\mathrm{L} \mathrm{s}^{-1}\right) ; Q_{\mathrm{fs}}$ is the total discharge flow-rate of fixed-speed pump units $\left(\mathrm{L} \mathrm{s}^{-1}\right) ; P_{\mathrm{abs}, \mathrm{i}}$ is the power capacity required by pumping station $(\mathrm{kW})$ in a given scenario; , ; being $\left(Q_{\mathrm{vs}}+Q_{\mathrm{fp}}\right)$ equals to $Q_{\mathrm{si}}$ or $Q_{\mathrm{di}}$ as appropriate.

In order to control the pressure head, a programmable logic controller (PLC) and a pressure transducer is usually installed at the pumping station. Shared regulation is usually employed in variable-speed pump units, i.e. all of them spin at the same speed and are always in operation. Initially only variable-speed pumps operate until the required discharge flow-rate surpasses its discharge capacity. At that moment one fixed-speed pump unit starts up. At this point in time the discharge flow-rate of all the fixed-speed pumps $Q$ can be derived using the Eq.(9) when the pressure head required at the origin of the network is $H_{\mathrm{i}}$. In order to obtain the number of fixed- 
1 speed pump units to supply the discharge-pressure needs, the integer of this quotient has to be

2 done:

3

$$
\mathrm{N}_{\mathrm{fs}}=\frac{\mathrm{Q}_{\mathrm{si}}}{\mathrm{Q}} \text { or } \frac{\mathrm{Q}_{\mathrm{di}}}{\mathrm{Q}} \text { as appropriate }
$$

4 Thus,

5

$$
\mathrm{Q}_{\mathrm{fs}}=\mathrm{QN}_{\mathrm{fs}}
$$

6 The discharge flow-rate of each variable-speed pump unit will be derived as follows:

7

$$
\mathrm{Q}_{1}=\frac{\left(\mathrm{Q}_{\mathrm{si}}-\mathrm{Q}_{\mathrm{fs}}\right)}{\mathrm{N}_{\mathrm{vs}}} \quad \text { or } \quad \mathrm{Q}_{1}=\frac{\left(\mathrm{Q}_{\mathrm{di}}-\mathrm{Q}_{\mathrm{fs}}\right)}{\mathrm{N}_{\mathrm{vs}}} \quad \text { as appropriate }
$$

9 Pump revs $\alpha$ could be obtained using the Eq.(10), after $Q_{1}$ is calculated.

$N_{\mathrm{vs}}$ have to be an attribute previously known of the pumping station.

11 Finally, the energy consumption when the network operates sectorized is given by:

$$
\mathrm{E}=\sum_{\mathrm{i}=1}^{\mathrm{NS}} \mathrm{P}_{\mathrm{abs}, \mathrm{i}} \mathrm{t}_{\mathrm{d}}
$$

13 Where $E$ is the daily energy consumption in the most water-demanding month, (July) in $\mathrm{kW} \mathrm{h} \mathrm{d}$

However, to obtain the energy consumption in on-demand operating networks, it is necessary to calculate the time the pumping station is working into each $Q_{\mathrm{di}}-H_{\mathrm{i}}$ point, using the relative frequency table derived from the Montecarlo simulation (Moreno et al., 2009). To this end, the discharge flow-rate range ( 0 to $\left.Q_{\mathrm{di}, \max }\right)$ was split in ten intervals (discharge deciles), and each one of them in ten pressure subintervals (pressure deciles $H_{\mathrm{i}, \min }$ to $H_{\mathrm{i}, \max }$ ). Calculating the relative frequency under which the pumping station works in each interval, was possible to infer the percentage of daily operation time -OT- the pumping station performs at a certain operating 
1 point $Q_{\mathrm{di}}-H_{\mathrm{i}}-\eta_{\mathrm{i}}$, and so obtain its energy consumption (one day in the the most water-demanding

2 month -July-, in $\mathrm{kW} \mathrm{h} \mathrm{d} \mathrm{d}^{-1}$ ).

\section{$3 \quad$ 2.5. Turn or Operating Sector arrangement}

4 The turns or operating sectors could be obtainedin a first stage by sorting out the hydrants

5 depending on their altitude in relation to that of the pumping station. The hydrants are placed

6 from lowest to highest and their discharge flow rates are summed up, forming NS turns with

7 similar $Q_{\text {s. }}$ Each one of those turns or sectors requirescertain pressure to ensure that at the most

8 unfavorable hydrant the pressure head is greater than the minimum required to operate the on-

9 farm irrigation system. If variable-speed pump units exist, the pumping station might adapt its

10 performance to the different turn pressure head requirementss. In this way some energy savings

11 should be expected with respect an alternative arrangement in which both low and high altitude

12 hydrants (which would require always high pressure). However, it is proved that this type of turn arrangement remains very inefficient if head losses were higher than the drop itself (GarcíaPrats et al., 2012).

Studying all the possible configurations in order to select the best one involves an unacceptably high computational effort (Lamaddalena and Sagardoy, 2000). Since it is not likely to explore all the existing open-hydrant combinations, we needed a method to allocate the hydrants to the best turn or sector from an energy point of view. We used the Simulated Annealing (SA) algorithm. SA is a heuristic algorithm of combinatorial optimization. The daily energy consumption $E\left(\mathrm{~kW} \mathrm{~h} \mathrm{~d}^{-1}\right)$ during one day of the peak demand month (July) (Eq.12) was employed as objective function. The kickoff scenario was an operating sector arranged according to the aforementioned method of the elevation criteria. In each iteration, the algorithm analyze a new configuration in the neighborhood of the previous one and its energy consumption is evaluated. The new configuration includes the whole set of hydrants working in the current turn or sector save one. One hydrant (from 1 to $n$ ) is selected at random, and one operating turn or sector (from 1 to $N S$ ) is selected at random as well. The chosen hydrant leaves 
1 the current turn and starts to operate in the selected one. This new scenario is simulated using

2 the EPANET model with the purpose to obtain the energy consumption. When the new scenario

3 is not hydraulically feasible or do not improve the objective function, will be immediately

4 rejected and a new one is searched for. When a hydraulically feasible scenario is obtained,

5 energy consumption has to be better than the one obtained in the previous scenario but may or

6 may not be accepted depending on the Metropolis criterion. In case of acceptance, this

7 combination was employed as the starting point for the next iteration, if not accepted the

8 previous one was used to start a new iteration. Further information on this algorithm can be

9 found in García-Prats et al. (2012).

10 In order to check the hydraulic feasibility, a turn or operative sector has to meet two criteria: a)

11 all the links of the network have a velocity lesser than $3 \mathrm{~m} \mathrm{~s}^{-1}, \mathrm{~b}$ ) the pressure is greater than

12 zero in non-operating hydrants and greater than $25 \mathrm{~m}$ in the operating hydrants and other nodes.

\subsection{Electricity tariff structure}

14 The electricity tariff is divided in two terms: the first one is related to the energy consumption and the second one that considers the maximum demand of power capacity. Both of them have a different price, according to the time of day at which the energy consumption takes place. The energy term is a Time of Use (TOU) rate with three different usage periods: OFF-PEAK ( $8 \mathrm{~h}$ per day), MID-PEAK (10 h per day) and PEAK ( $4 \mathrm{~h}$ per day) with charges that vary accordingly. The power capacity term is a Demand Rate Tariff (DR). Users have to contract for a certain power capacity. The electricity meter registers the maximum value of instantaneous power capacity demanded during the entire usage period. If the maximum power capacity registered takes a value less than $105 \%$ of the contracted capacity, the bill will be for the contracted power capacity, otherwise a high penalty will be applied on the off-contract power used. This means that customers normally contract for a sufficient capacity to meet their normal maximum requirements. Power capacity demanded during each usage period is invoiced to its specific price. 
1

\subsection{Case Study}

2 The area chosen to test the energy effect of new strategies of on-farm irrigation management

was a traditionally irrigated citrus-growing area in the Valencian Community, region located in the east of Spain . Since 1998, when the collective irrigation facilities were modernized, the system employed to distribute irrigation water is a flow-driven pipeline distribution network. The on-farm irrigation system installed was drip irrigation. This method substituted the previous canal and the on-farm surface irrigation system. The total irrigated area is 191.15 ha with a total of 382 hydrants in individual plots, clustered in 47 control units. The pumping station has three $N_{0}=2900 \mathrm{rpm}$ and $63 \mathrm{kWpumps}$. Only one pump is variable-speed -i.e. equipped with an adjustable frequency drive- being the others fixed-speed pump units. The pump coefficients derived taking into account the characteristic curves supplied by the manufacturer were: $\mathrm{F}=$ $0.021631 ; \mathrm{E}=2.546664 ; \mathrm{D}=-0.007729 ; \mathrm{C}=120.228854$.

Peak gross crop irrigation requirements (calculated as average of July) was $3.95 \mathrm{~L} \mathrm{~m}^{-2} \mathrm{~d}^{-1}$. Since the landscape is high parceled, a single subunit $N_{\mathrm{s}}$ per plot was found, and therefore $\mathrm{t}_{r}=t_{\mathrm{d}}$. The irrigation interval $(I R)$ was fixed at 1 due to the fact that in drip irrigation watering usually take place on a daily basis.

$A_{\mathrm{rs}}$ was defined as the average on-farm irrigation system application rate $\left(\mathrm{L} \mathrm{m}^{-2} \mathrm{~h}^{-1}\right)$. The crop pattern encountered in this area is the one typical used for Citrus trees with 375 plants per hectare and 8 drippers with an emitter discharge $q_{\mathrm{e}}=4 \mathrm{~L} \mathrm{~h}^{-1}$. Therefore $A_{\mathrm{rs}}$ :

$$
\mathrm{A}_{\mathrm{rs}}=375 \times 8 \times 4=12,000 \mathrm{~L} \mathrm{~h}^{-1} \mathrm{ha}^{-1}=1.2 \mathrm{Lh}^{-1} \mathrm{~m}^{-2}
$$

Irrigation-related variables $t_{\mathrm{d}}$ and $d_{\mathrm{i}}$ were derived as follows:

$$
\mathrm{t}_{\mathrm{r}}=\frac{\mathrm{NT}_{\mathrm{r}} \mathrm{IR}}{\mathrm{A}_{\mathrm{rs}}}=\frac{3.95 \mathrm{xl}}{1.2}=3.29 \mathrm{~h} \quad \mathrm{~d}_{\mathrm{i}}=2.778 \mathrm{~A}_{\mathrm{rs}} \frac{\mathrm{S}_{\mathrm{i}}}{\mathrm{N}_{\mathrm{s}}}=3.336 \mathrm{~S}_{\mathrm{i}}
$$

The pressurized irrigation network currently works on-demand with an operation time OT $=16$ $\mathrm{h} \mathrm{d}^{-1}$ in order to avoid paying the peak-rate tariff. Five operating sectors $(N S)$ are close to $16 \mathrm{~h} \mathrm{~d}^{-}$ 
$1{ }^{1}$ because $3.29 \mathrm{~h} \times 5=16.45 \mathrm{~h} \mathrm{~d}^{-1}$. In order to compare homogeneous results between on-

2 demand and sectorized performance, in on-demand performance scenarios $O T$ was adapted to

3 the sectorized $O T$ obtained for each simulated scenario. Hence, when the current on-demand

4 performance was compared with sectorized operations, on-demand $O T$ was fixed at $16.45 \mathrm{~h} \mathrm{~d}^{-1}$

5 in order to compare the results for all the analyzed scenarios.

6 Table 1 summarizes the 2015 electricity tariffs.

8 Finally, applying Eq. (4) we obtain the last related irrigation parameter $p_{\mathrm{i}}$ :

9

Please Insert Table 1 here

$$
\mathrm{p}_{\mathrm{i}}=\frac{\mathrm{N}_{\mathrm{s}} \mathrm{t}_{\mathrm{r}}}{\text { OT IR }}=\frac{1 \times 3.29}{16.45 \mathrm{x} 1}=0.2
$$

\subsection{Continuous and pulsed irrigation scenarios} under pulsed irrigation with two and three pulses, respectively.

As the analyzed network and its pumping station were designed to work as described above, we did not search for more demanding scenarios (with lower NS-OT and higher $p_{\mathrm{i}}$ ) as they would not have been hydraulically feasible. However the network is able to work with lower emitter discharges and higher NS-OT values when the discharge is maintained at the current value $\left(q_{\mathrm{e}}=4\right.$ $\left.\mathrm{L} \mathrm{h}^{-1}\right)$. As pulsed irrigation was only expected to affect on-demand performance, the scenarios analyzed were those shown in Table 2. Each scenario was simulated under 5 different performance conditions: 1) SecElv: sectorized operation by first arranging the hydrants according to their elevation, 2) SecSA: sectorized following the above-described SA optimization procedure in order to obtain the best hydrant arrangement, 3) Dem1: operating ondemand under continuous irrigation (one pulse), and 4) Dem2 - 5) Dem3: operating on-demand 


\section{Results and discussion}

3 As can be seen in Table 2, 46 different scenarios were considered to show the effect on energy

4 consumption of new irrigation management strategies (Continuous and pulsed irrigation) in 5 pressurized irrigation networks.

\section{$6 \quad$ 3.1. Continuous irrigation}

7 All the scenarios under continuous irrigation management were assessed first (SecElv-SecSA-

8 Dem1 in Table 2). Figures $1 \mathrm{a}, \mathrm{b}$ and $\mathrm{c}$ show the evolution of $P_{\mathrm{abs}}(\mathrm{kW})$, power capacity, $E$ $9 \quad(\mathrm{~kW} \cdot \mathrm{h})$, daily energy consumption in the most water-demanding month (July) and $E C(€)$ 10 electricity costs for the same period in the different scenarios.

Please Insert Figure 1 here

Comparing the different scenarios: Scenarios 1, 2 and 3 represent the current on-farm irrigation system with increased $O T$ and $N S$. Scenarios 4, 5 and 6 have different emitter discharge rates from Scenarios 1, 2 and 3. Now $q_{\mathrm{e}}=3 \mathrm{~L} \mathrm{~h}^{-1}$ instead of $q_{\mathrm{e}}=4 \mathrm{~L} \mathrm{~h}^{-1}$. Irrigation time thus needs to be longer, and three different scenarios could be created, keeping $O T$ near the $16<O T<24 \mathrm{~h}$ range, as can be seen in Table 2. Scenarios 7 and 8 were formed using $q_{\mathrm{e}}=2 \mathrm{~L} \mathrm{~h}^{-1}$. Scenarios 9 and 10 were obtained for $q_{\mathrm{e}}=1 \mathrm{~L} \mathrm{~h}^{-1}$ and $q_{\mathrm{e}}=0.8 \mathrm{~L} \mathrm{~h}^{-1}$ respectively.

As can be seen in Figure 1, when all the performance types were compared, the following rule can be derived regardless of the scenario analyzed: $P_{\text {abs }}$ in both sectorized performance types (SecElv and SecSA) showed similar behavior, requiring considerably less power capacity than Dem1. Focusing on the energy consumption $E$, Dem1 was characterized by a high-energy demand, followed closely by SecElev, while SecSA required significantly less energy. 
1 However, when $E$ was translated into energy costs $E C$, this effect became more pronounced and

2 SecElev and Dem1 showed similar very high $E C$ while SecSA showed lower $E C$ values.

3 It can be seen that, as a general rule, irrigation networks in on-demand or sectorized operations

4 in which the operating sectors have been designed without any or with incorrect criteria leads to

5 a high-energy demand and energy costs. However, if optimization techniques are used to

6 organize hydrant performance, considerable energy and cost savings can be achieved (García-

7 Prats et al., 2012; Jimenez-Bello et al., 2015).

8 In the analysis of specific scenarios, comparing the current on-farm irrigation system (Scenario

91 compared to itself i.e. compared to Scenarios 2 and 3, the observed abatement of capacity $P_{\text {abs }}$ obtained by increasing $N S$ and $O T$, only gave energy savings in SecSA performance, but in no case showed cost savings. We can therefore see that the decision of the network managers to limit the $O T$ to OFF-PEAK and MID-PEAK to avoid the PEAK period was a good choice.

In Scenarios 4, 5 and 6, as regards $P_{\text {abs }}$, increasing $O T$ and $N S$ lowered the required capacity in all types of performance. However, $E$ only decreased in SecSA and increased in the other two types. $E C$ increased in all types of performance. The same trend was observed in Scenarios 5 and 6. All the performance types tend to converge in Scenarios 9 and 10, due to the lack of

17 freedom to irrigate.

However, comparing the scenarios that use the current emitter discharge rate of $q_{\mathrm{e}}=4 \mathrm{~L} \mathrm{~h}^{-1}$ (Scenarios 1, 2 and 3) with those that use the lower rate of $q_{\mathrm{e}}=3 \mathrm{~L} \mathrm{~h}^{-1}$ etc. (Scenarios 4, 5 and 6) we see that the results depend on $O T$ and $N S$. Table 3 summarizes the maximum differences obtained by comparing the current Scenario 1 with the most efficient scenario, expressed in absolute values and percentages, excluding Scenarios 2 and 3, which belong to the current onfarm irrigation system $\left(q_{\mathrm{e}}=4 \mathrm{~L} \mathrm{~h}^{-1}\right)$. 
3 Reductions in $q_{\mathrm{e}}$ and $E-E C$ savings are not inherently related to each other. A certain amount of

$4 \quad E$ and $E C$ could be saved when $N S$ and $O T$ parameters are properly selected, especially when

5 the network operates on-demand. In addition, the interaction between the energy variables $O T$

6 and NS with the power company's billing structure must be taken into account, since energy

7 savings are not always translated into cost savings. For example, for Dem1, Scenarios 7 and 8

8 showed $E$ savings over Scenario 1, but only Scenario 7 had $E C$ savings. On the other hand,

9 Scenario 8 showed a considerable increase in $E C$ due to the use of power during the peak time.

10 To sum up, as the best results were obtained by using optimization techniques (SecSA

11 scenarios) to organize operating hydrants, and similar $E C$ could be obtained with different

12 emitter discharges. Hence, the main potential for savings in $E$ and $E C$ could be related to on-

13 demand performance.

\subsection{Pulsed irrigation}

This section gives the results of the pulsed-irrigation scenarios (Dem1-Dem2-Dem3) with one, two or three pulses (see Table 2). Table 5 summarizes the $P_{\text {abs }}-E-E C$ obtained in these scenarios. Figures $2 \mathrm{a}, \mathrm{b}$ and $\mathrm{c}$ show the evolution of $P_{\mathrm{abs}}-E-E C$ in the different scenarios.

As can be seen in Figure 2, when the number of pulses is compared the following rule can be derived: $P_{\text {abs }}$ in all cases (Dem1, Dem2, and Dem3) showed similar behavior and the higher the pulse rate the less the $P_{\text {abs }}$ required. Focusing on energy consumption $E$, performance was characterized by a decrease in energy consumption, i.e. energy demand dropped with more 
1 pulses. When $E$ was translated into energy costs $E C$, this effect still remained. We can thus

2 claim that, as a general rule, in irrigation networks operating on-demand, pulsed irrigation leads

3 to savings in power capacity, energy demands and electricity costs. In Scenario 1 pulsed

4 irrigation showed an energy saving potential of $10.67,6.43$ and $6.99 \%$ for $P_{\text {abs, }} E$ and $E C$,

5 respectively.

6 Analyzing specific scenarios, starting with the current on-farm irrigation system (Scenario 1)

7 compared to itself, and Scenarios 2 and 3: increasing $O T$ in all cases showed a drop in $P_{\text {abs, }}$, but

8 in no case resulted in $E$ or $E C$ savings. Hence, the decision made by the network managers to

9 limit $O T$ to OFF-PEAK and MID-PEAK usage periods to avoid the PEAK period is also seen to

10 be a good choice in pulsed irrigation. Exactly the same behavior was observed for Scenarios 4-

$11 \quad 5-6$ and 7-8.

12 Nevertheless, comparing the scenarios formed by the current emitter discharge rate of $q_{\mathrm{e}}=4 \mathrm{~L} \mathrm{~h}^{-1}$

13 (Scenarios 1, 2 and 3) with those at the lower discharge rate of $q_{\mathrm{e}}=3 \mathrm{~L} \mathrm{~h}^{-1}$ etc. (Scenarios 4, 5

14 and 6), we observe that the most important parameter was $O T$ and its interaction with the billing

15 structure. Scenarios with similar $O T$ had similar $E$ and $E C$, regardless of emitter discharge rate,

16 e.g. Scenario 1 vs Scenario 4. As happened in the continuous irrigation scenarios, increasing $O T$

17 reduced $P_{\text {abs }}$ but increased $E$ and $E C$.

\section{Conclusions}

In this work forty-six different scenarios were considered to illustrate the effect on energy requirements of new irrigation management strategies (Continuous and pulsed irrigation) in pressurized irrigation networks.

23 Continuous irrigation in networks operating on-demand or sectorized with sectors created

24 without any criteria lead to high energy demands and thus high energy costs. However, significant energy and cost savings can be achieved by employing optimization techniques to 
organize hydrants performance that proved to be crucial. These savings can be consolidated when new strategies of on-farm irrigation management are implemented. However reduced $q_{\mathrm{e}}$ and $E$-EC savings are not inherently related to each other. A certain amount of $E$ and $E C$ can be saved when $N S$ and $O T$ parameters are carefully selected, especially operating on-demand. It is also crucial to take into account the interaction between the $O T$ and $N S$ energy variables with the electricity billing structure, since energy savings are not always translated into cost savings, especially when peak time electricity is used.

Pulsed irrigation in networks operating on-demand leads to savings in power capacity, energy demand and electricity costs. The most important parameter related to energy savings was $O T$ and its associated interaction with the billing structure. Scenarios with similar $O T$ showed similar $E$ and $E C$, regardless of emitter discharge rate.

To conclude, the adoption of new on-farm irrigation management techniques (low discharge rates, long irrigation times and high frequencies or pulsed irrigation) have been shown to have energy saving potential, especially in networks operating on-demand. However, the new scenarios have to be analyzed taking into account the interaction of the billing structure with the irrigation performance parameters in order to prevent the opposite effect to that intended.

\section{Acknowledgements}

The study has been partially funded by the IMPADAPT project (CGL2013-48424-C2-1-R) with Spanish MINECO (Ministerio de Economía y Competitividad) and Feder funds.

The authors would like to thank the editor and reviewers for their valuables suggestions. 
Alandi P.P., Martín-Benito J.M.T., Alvarez J.F.O., Martínez M.I.C., 2001. Design of water distribution networks for on-demand irrigation. Irrig. Sci. 20, 189-201.

Assouline S., 2002a. The effects of microdrip and conventional drip irrigation on water distribution and uptake. Soil Sci. Soc. Am. J. 66, 1630-1636.

Assouline S., Cohen S., Meerbach D., Harodi T., Rosner M., 2002b. Microdrip irrigation of field crops: Effect on yield, water uptake, and drainage in sweet corn. Soil Sci. Soc. Am. J. $66,228-235$.

Brouwer C., Prins C., Kay M., Heibloem M., 1988. Irrigation Water Management: Irrigation Methods. Training Manual No. 5. Food and Agricultural Organisation of the United Nations, Rome.

Clément R., 1966. Calcul des debits dans les reseaux d'irrigation fonctionant a la demande. Houille Blanche, 5, 553-575.

Cote C.M., Bristow K.L., Charlesworth P.B., Cook F.J., Thorburn P.J., 2003. Analysis of soil wetting and solute transport in subsurface trickle irrigation. Irrig. Sci. 22, 143-156.

Daccache A., Weatherhead K., Lamaddalena N., 2010. Climate change and the performance of pressurized irrigation water distribution networks under mediterranean conditions: Impacts and adaptations. Outlook Agric. 39, 277-283.

Daccache A., Lamaddalena N., Fratino U., 2010. On-demand pressurized water distribution system impacts on sprinkler network design and performance. Irrig. Sci. 28, 331-339.

Daccache A., Lamaddalena N., Fratino U., 2010. Assessing pressure changes in an ondemand water distribution system on drip irrigation performance-case study in Italy. J. Irrig. Drain. Eng. 136, 261-270.

Díaz J.A.R., Luque R.L., Cobo M.T.C., Montesinos P., Poyato E.C., 2009. Exploring energy saving scenarios for on-demand pressurised irrigation networks. Biosyst. Eng. 104, 552561.

Elmaloglou S. and Diamantopoulos E., 2007. Wetting front advance patterns and water losses by deep percolation under the root zone as influenced by pulsed drip irrigation. Agric. Water Manage. 90, 160-163.

Elnesr, M.N., Alazba, A.A., 2015. The effects of three techniques that change the wetting patterns over subsurface drip-irrigated potatoes. Spanish J. Agric. Res. 13, e1204.

Elnesr, M.N., Alazba, A.A., Zein El-Abedein, A.I., El-Adl, M.M., 2015. Evaluating the Effect of Three Water Management Techniques on Tomato Crop. PLoS One 10, e0129796.

Fernández García I., Moreno M.A., Rodríguez Díaz J.A., 2014. Optimum pumping station management for irrigation networks sectoring: Case of Bembezar MI (Spain). Agric. Water Manage. 144, 150-158.

Fernández García I., Montesinos P., Camacho Poyato E., Rodríguez Díaz J.A., 2015. Energy cost optimization in pressurized irrigation networks. Irrig. Sci.

Fernández García I., Rodríguez Díaz J.A., Camacho Poyato E., Montesinos P., 2013. Optimal Operation of Pressurized Irrigation Networks with Several Supply Sources. Water Resour. Manage. 27, 2855-2869. 
García-Prats A., Guillem-Picó S., Martinez-Alzamora F., Jimenez-Bello M.A., 2012. Random scenarios generation with minimum energy consumption model for sectoring optimization in pressurized irrigation networks using a simulated annealing approach. $\mathrm{J}$. Irrig. Drain. Eng. 138, 613-624.

González Perea R., Camacho Poyato E., Montesinos P., Rodríguez Díaz J.A., 2014. Critical points: Interactions between on-farm irrigation systems and water distribution network. Irrig. Sci. 32, 255-265.

IDAE, 2008. Protocolo de auditoría energética en Comunidades de Regantes. Ministerio de Industria, Turismo y Comercio, Spain. 68 pp.

Jiménez-Bello M.A., Martínez Alzamora F., Bou Soler V., Ayala H.J.B., 2010. Methodology for grouping intakes of pressurised irrigation networks into sectors to minimise energy consumption. Biosyst. Eng. 105, 429-438.

Jiménez-Bello M.A., Royuela A., Manzano J., Prats A.G., Martínez-Alzamora F., 2015. Methodology to improve water and energy use by proper irrigation scheduling in pressurised networks. Agric. Water Manage. 149, 91-101.

Lamaddalena N., Sagardoy J.A., 2000. Performance Analysis of On-demand Pressurized Irrigation Systems. Paper 59. FAO. Irrigation and Drainage, Rome, Italy.

Lamaddalena N., Fratino U., Daccache A., 2007. On-farm Sprinkler Irrigation Performance as affected by the Distribution System. Biosyst. Eng. 96, 99-109.

Monserrat J., Poch R., Colomer M.A., Mora F., 2004. Analysis of Clément's first formula for irrigation distribution networks. J. Irrig. Drain. Eng. 130, 99-105.

Moreno M.A., Planells P., Ortega J.F., Tarjuelo J., 2007. New methodology to evaluate flow rates in on-demand irrigation networks. J. Irrig. Drain. Eng. 133, 298-306.

Moreno M.A., Planells P., Córcoles J.I., Tarjuelo J.M., Carrión P.A., 2009. Development of a new methodology to obtain the characteristic pump curves that minimize the total cost at pumping stations. Biosyst. Eng. 102, 95-105.

Phogat V., Skewes M.A., Mahadevan M., Cox J.W., 2013. Evaluation of soil plant system response to pulsed drip irrigation of an almond tree under sustained stress conditions. Agric. Water Manage. 118, 1-11.

Phogat V., Skewes M.A., Cox J.W., Mahadevan M., 2012. Modelling the impact of pulsing of drip irrigation on the water and salinity dynamics in soil in relation to water uptake by an almond tree. WIT Trans. Ecol. Environ. 168, 101-113.

Planells Alandi P., Carrión Pérez P., Ortega Álvarez J.F., Moreno Hidalgo M.A., Tarjuelo Martín-Benito J.M., 2005. Pumping selection and regulation for water-distribution networks. J. Irrig. Drain. Eng. 131, 273-281.

Plusquellec H., 2009. Modernization of large-scale irrigation systems: Is it an achievable objective or a lost cause. Irrig. Drain. 58, S104-S120.

Rachev S.T., Höchstötter M., Fabozzi F. J., Focardi S. M., 2006. Financial Modeling of the Equity Market, John Wiley \& Sons, Inc., Hoboken, NJ, USA.

Rodríguez Díaz J.A., Camacho Poyato E., López Luque R., 2007. Model to forecast maximum flows in on-demand irrigation distribution networks. J. Irrig. Drain. Eng. 133, 222-231. 
Rodríguez Díaz, J.A., Montesinos, P., Poyato, E.C., 2012. Detecting Critical Points in OnDemand Irrigation Pressurized Networks - A New Methodology. Water Resour. Manag. 26, 1693-1713.

Rossman L.A., 2000. Epanet user manual, U.S. Environmental Protection Agency, Drinking Water Research Division, Risk Reduction Engineering Laboratory, Cincinnati.

Savage S. L., 2003. Decision making with insight, Thomson-Brooks/Cole, Belmont, N.C.

Segal E., Ben-Gal A., Shani U., 2006. Root water uptake efficiency under ultra-high irrigation frequency. Plant Soil. 282, 333-341.

Silber A., Israeli Y., Elingold I., Levi M., Levkovitch I., Russo D., Assouline S., 2015. Irrigation with desalinated water: A step toward increasing water saving and crop yields. Water Resour. Res. 51, 450-464.

Skaggs T.H., Trout T.J., Rothfuss Y., 2010. Drip irrigation water distribution patterns: Effects of emitter rate, pulsing, and antecedent water. Soil Sci. Soc. Am. J. 74, 1886-1896.

Smith R.J., Baillie J.N., McCarthy A.C., Raine S.R., Baillie C.P., 2010. Review of Precision Irrigation Technologies and their Application. National Centre of Engineering in Agriculture, University of Southern Queensland, Toowoomba NCEA Publication $1003017 / 1$.

Tarjuelo J.M., Rodriguez-Diaz J.A., Abadía R., Camacho E., Rocamora C., Moreno M.A., 2015. Efficient water and energy use in irrigation modernization: Lessons from Spanish case studies. Agric. Water Manage. 162, 67-77.

Vyrlas P. and Sakellariou M. 2005. Intermittent water application through surface and subsurface drip irrigation. 2005 ASAE annual international meeting.

Zou X., Li Y., Cremades R., Gao Q., Wan Y., Qin X., 2013. Cost-effectiveness analysis of water-saving irrigation technologies based on climate change response: A case study of China. Agric. Water Manage. 129, 9-20. 
2

Table 1. Usage period-related 2015 electricity tariffs.

\begin{tabular}{cccc} 
& OFF-PEAK & MID-PEAK & PEAK \\
Capacity $\left(€ \cdot \mathrm{kW}^{-1} \cdot \mathrm{d}^{-1}\right)$ & 0.0229 & 0.0997 & 0.1622 \\
Energy $\left(€ \cdot \mathrm{kW} \cdot \mathrm{h}^{-1}\right)$ & 0.0684 & 0.1120 & 0.1267 \\
\hline
\end{tabular}

3

4

5

6 
2 Table 2. Scenarios analyzed under continuous and pulsed irrigation

\begin{tabular}{|c|c|c|c|c|c|c|c|}
\hline Scenario & \#Scenarios & Performance type & $q_{\mathrm{e}}\left(\mathrm{L} \mathrm{h}^{-1}\right)$ & NS & $t_{\mathrm{d}}(\mathrm{h})$ & $O T(h)^{*}$ & $p_{\mathrm{i}}$ \\
\hline 1 & 5 & SecElv-SecSA-Dem1-Dem2-Dem3 & 4 & 5 & 3.29 & 16.45 & 0.20 \\
\hline 2 & 5 & SecElv-SecSA-Dem1-Dem2-Dem3 & 4 & 6 & 3.29 & 19.74 & 0.17 \\
\hline 3 & 5 & SecElv-SecSA-Dem1-Dem2-Dem3 & 4 & 7 & 3.29 & 23.03 & 0.14 \\
\hline 4 & 5 & SecElv-SecSA-Dem1-Dem2-Dem3 & 3 & 3 & 4.39 & 13.17 & 0.33 \\
\hline 5 & 5 & SecElv-SecSA-Dem1-Dem2-Dem3 & 3 & 4 & 4.39 & 17.56 & 0.25 \\
\hline 6 & 5 & SecElv-SecSA-Dem1-Dem2-Dem3 & 3 & 5 & 4.39 & 21.95 & 0.20 \\
\hline 7 & 5 & SecElv-SecSA-Dem1-Dem2-Dem3 & 2 & 2 & 6.58 & 13.08 & 0.50 \\
\hline 8 & 5 & SecElv-SecSA-Dem1-Dem2-Dem3 & 2 & 3 & 6.58 & 19.74 & 0.33 \\
\hline 9 & 3 & SecElv-SecSA-Dem1* & 1 & 1 & 13.17 & 13.17 & 1.00 \\
\hline 10 & 3 & SecElv-SecSA-Dem $1 *$ & 0.8 & 1 & 16.45 & 16.45 & 1.00 \\
\hline
\end{tabular}

$3 \mathrm{q}_{\mathrm{e}}=$ emitter discharge; $\mathrm{NS}=$ number of sectors; $\mathrm{t}_{\mathrm{d}}=$ average daily irrigation time; $\mathrm{OT}=$ network

4 daily operation time and $\mathrm{p}_{\mathrm{i}}=$ probability that hydrant $i$ is open.

$5 \quad * O T=N S t_{\mathrm{d}}$

$6 *$ With this low emitter discharge rate only one pulse is possible per day.

7

8 Table 3. Increase in $P_{\text {abs }}(\mathrm{kW}), E(\mathrm{~kW} \mathrm{~h})$ and $E C(€)$ over Scenario 1, excluding Scenarios 2 and 93.

\begin{tabular}{c|ccc|ccc|ccc}
\hline \multicolumn{3}{c}{$P_{\text {abs }}(\mathrm{kW})$} & \multicolumn{3}{c}{$E(\mathrm{~kW} \cdot \mathrm{h})$} & \multicolumn{3}{c}{$E C(€)$} \\
\hline & SecElv & SecSA & Dem1 & SecElv & SecSA & Dem1 & SecElv & SecSA & Dem1 \\
\hline B.S. & 6 & 10 & 10 & 10 & 6 & 10 & 9 & 4 & 10 \\
$\Delta^{*}$ & 66.8 & 19.91 & 125.7 & 358.96 & 98.75 & 225.43 & 40.82 & 2.17 & 36.75 \\
$\Delta_{\%}$ & 36.03 & 13.69 & 49.66 & 14.81 & 4.82 & 9.71 & 16.83 & 1.06 & 15.14 \\
\hline W.S & 4 & 4 & 4 & 6 & 7 & 6 & 6 & 6 & 6 \\
$\Delta^{*}$ & -12.42 & -71.95 & -2.6 & -33.08 & -78.08 & -29.33 & -34.06 & -28.59 & -49.1 \\
$\Delta \%$ & -6.70 & -49.48 & -1.03 & -1.37 & -3.81 & -1.26 & -14.04 & -14.02 & -20.23 \\
\hline
\end{tabular}

$10 \quad \Delta^{*}$ : Saving as absolute value, $\Delta \%$ Saving as percentage, B.S=Best Scenario, W.S=Worst Scenario

$11 \mathrm{P}_{\mathrm{abs}}=$,power capacity; $\mathrm{E}=$ =nergy consumption for one day of irrigation in the peak month and

$12 \mathrm{EC}=$ electricity costs for the same period in the different scenarios. 
1

2 FIGURES

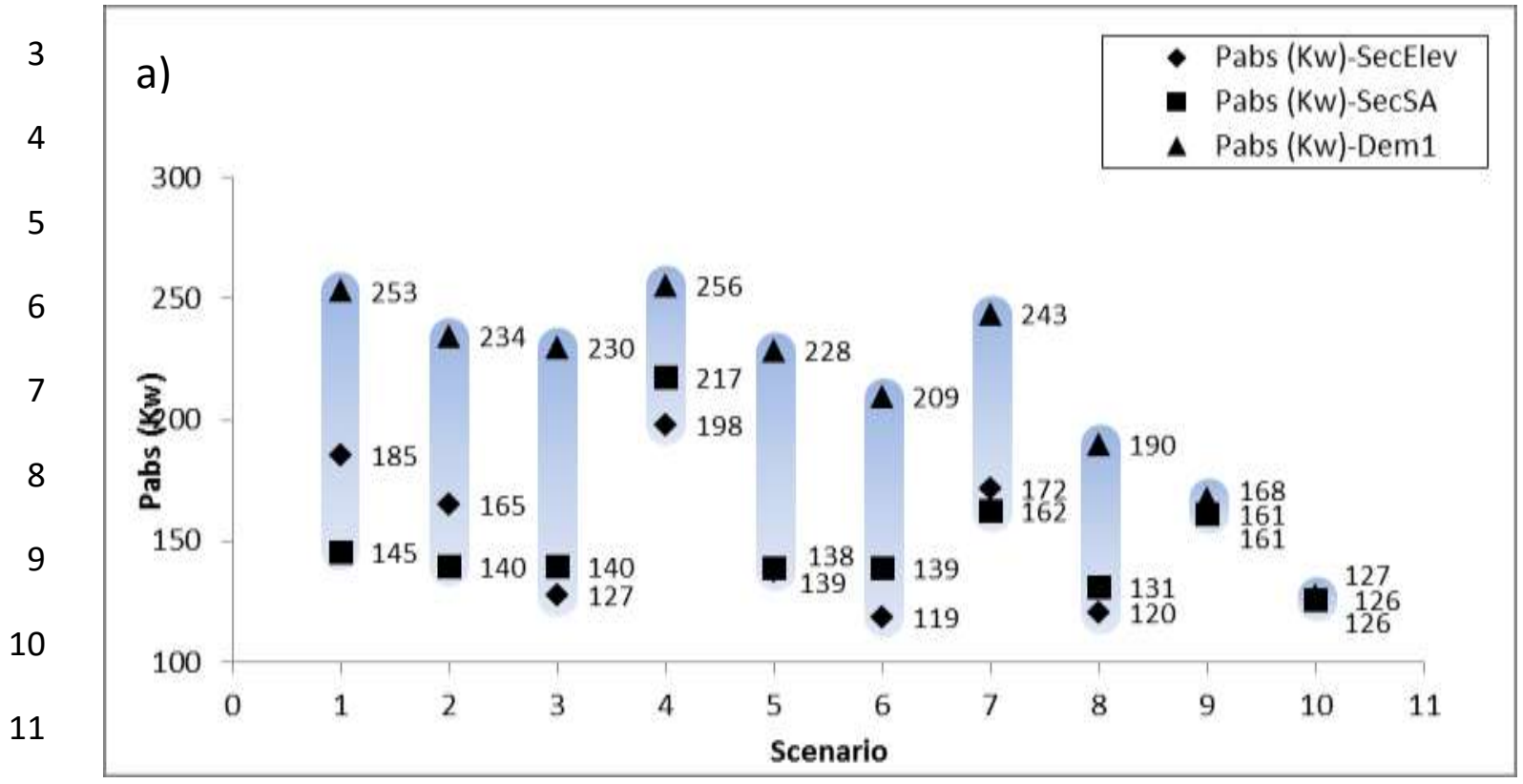

12

13

14

b)

15

16

17

18

19

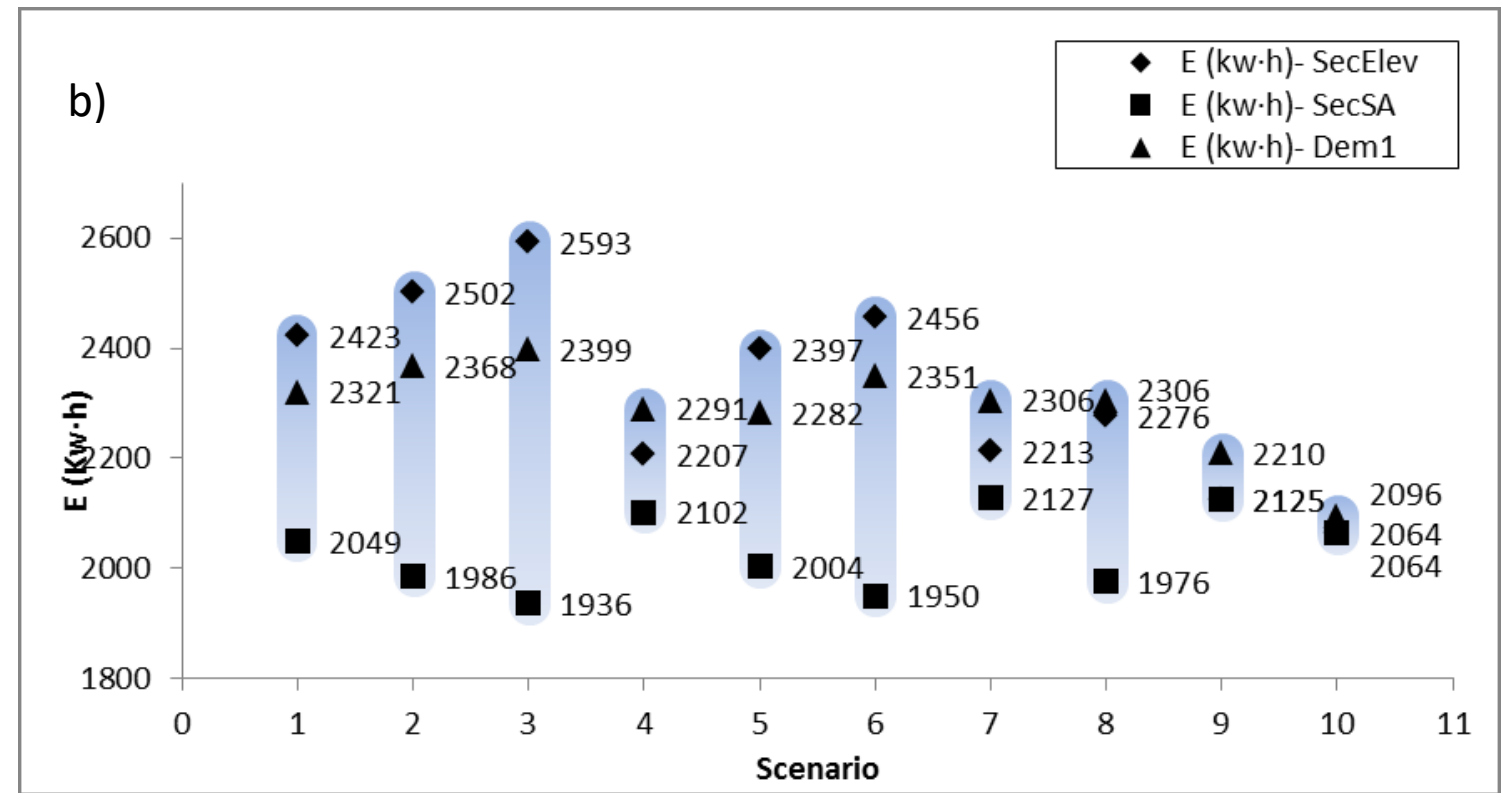




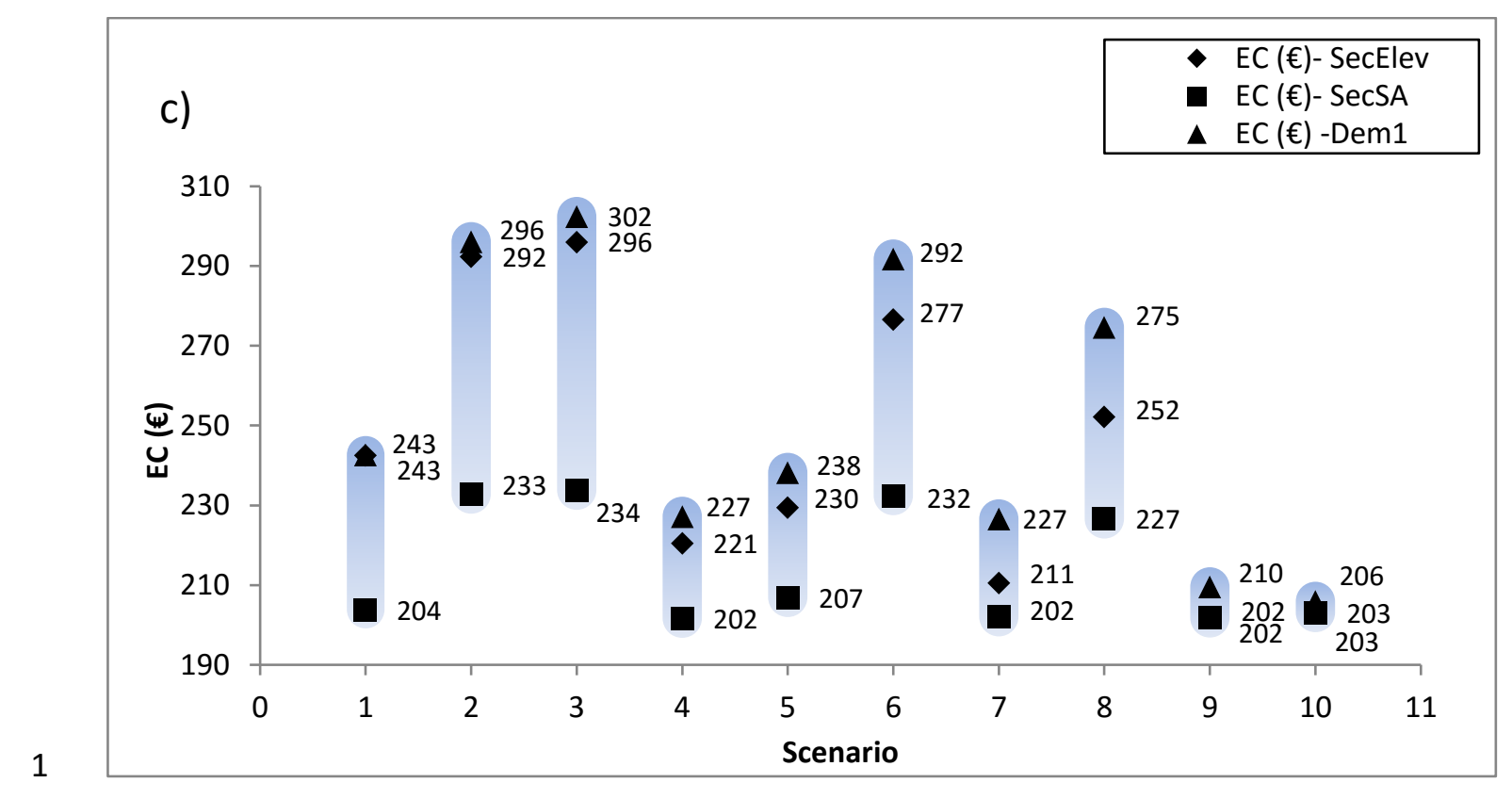

2 Figure 1. Evolution of $P_{\mathrm{abs}}(\mathrm{kW}), E(\mathrm{Kh} \mathrm{h})$ and $E C(€)$ in different scenarios of continuous

3 irrigation. $\mathrm{P}_{\mathrm{abs}}=$,power capacity; $\mathrm{E}=$ energy consumption for one day of irrigation in the peak 4 month and $\mathrm{EC}=$ electricity costs for the same period in the different scenarios. 

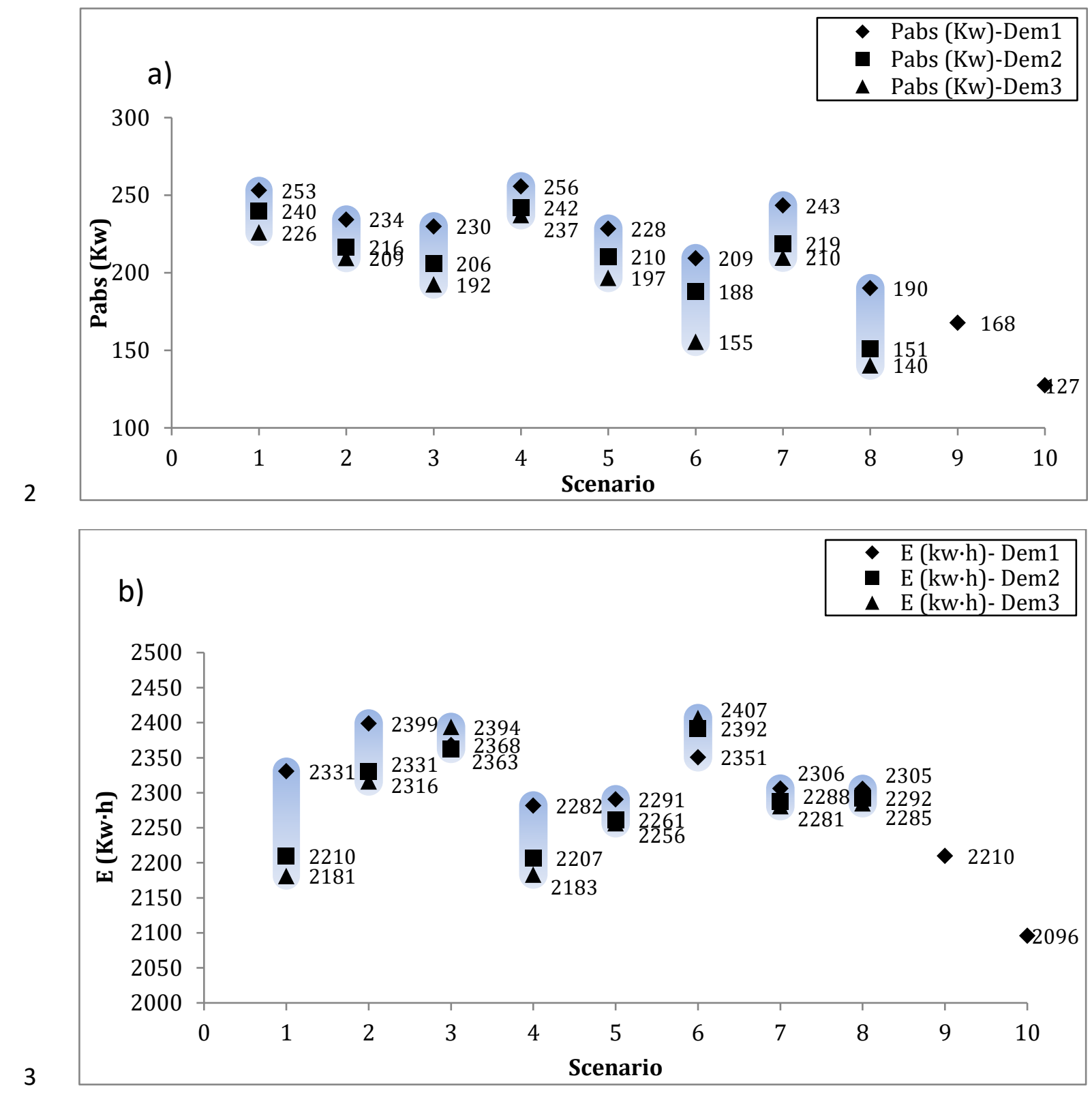


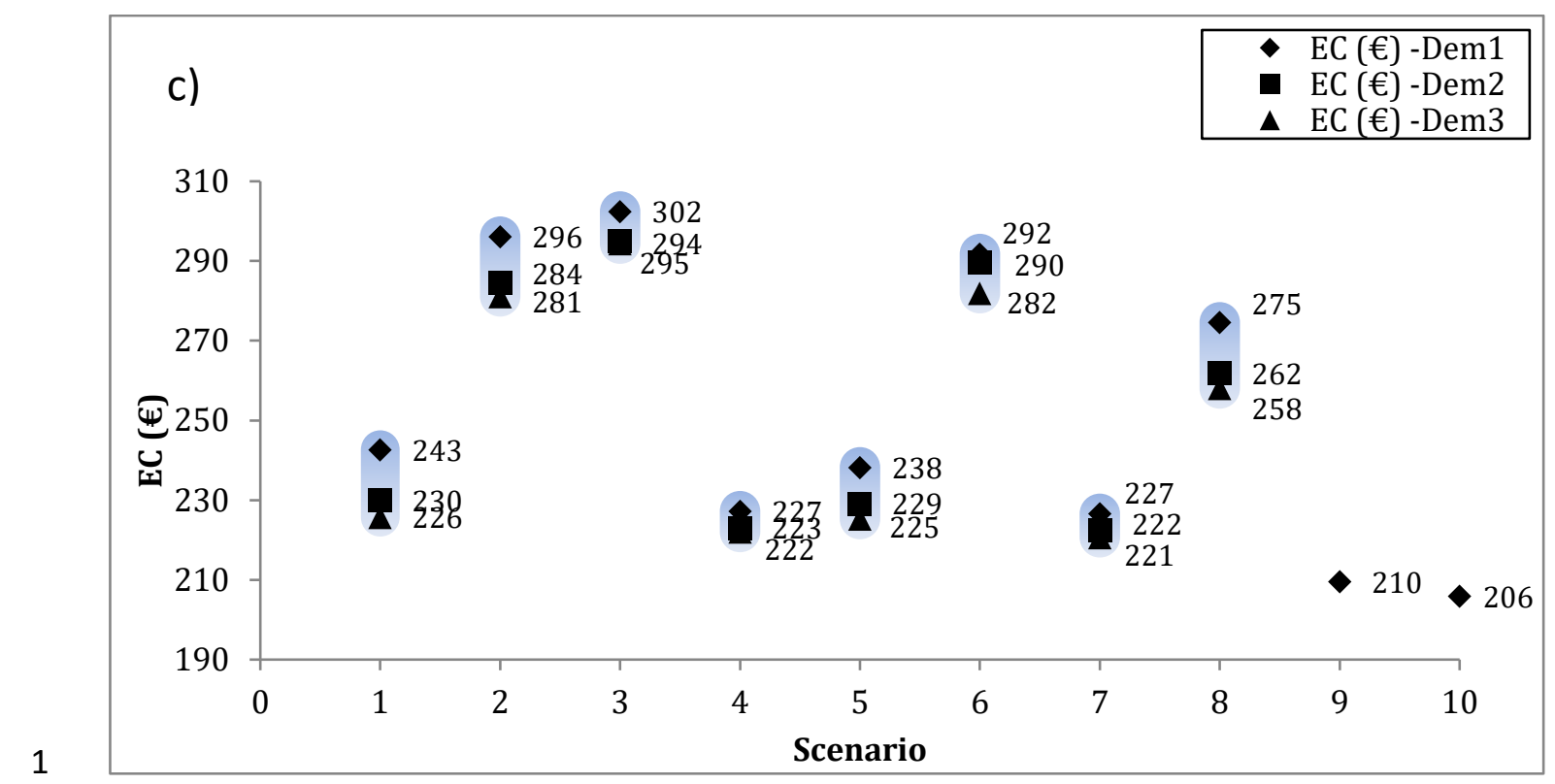

2 Figure 2. Evolution of $P_{\text {abs }}(\mathrm{kW}), E(\mathrm{~kW} \mathrm{~h})$ and $E C(€)$ in different scenarios of pulsed irrigation.

$3 \mathrm{P}_{\mathrm{abs}}=$,power capacity; $\mathrm{E}=$ energy consumption for one day of irrigation in the peak month and $4 \quad \mathrm{EC}=$ electricity costs for the same period in the different scenarios. 